\title{
The Politics of Environment in Ethiopia: The Policies and Practices Appraisal Since 1991
}

\author{
Sebsib Hadis ${ }^{1}$, Mulugeta Tesfaye ${ }^{1}$, Shimellis Hailu ${ }^{2}$ \\ ${ }^{1}$ Department of Peace and Development Studies, Wollo University, Dessie, Ethiopia \\ ${ }^{2}$ Department of Political Science and International Relations, Wollo University, Dessie, Ethiopia
}

Email address:

hadissebsib@gmail.com (S. Hadis), mulugetaabateee@gmail.com (M. Tesfaye), shimellishailu@yahoo.com (S. Hailu)

\section{To cite this article:}

Sebsib Hadis, Mulugeta Tesfaye, Shimellis Hailu. The Politics of Environment in Ethiopia: The Policies and Practices Appraisal Since 1991. Advances in Sciences and Humanities. Vol. 5, No. 4, 2019, pp. 88-97. doi: 10.11648/j.ash.20190504.11

Received: July 8, 2019; Accepted: July 30, 2019; Published: August 13, 2019

\begin{abstract}
This article analyzes the Ethiopian environmental policy and practices since 1991. This paper employs a set of principles and frameworks that Weimer \&Vining developed as grand principles of environmental policy and practices. The review is an attempt to analyze the international environmental engagements of Ethiopia vis-à-vis the domestic environmental policy practices. To properly address the issue, qualitative research approach and content analysis design are employed. The review consulted a multiple of secondary sources from different institutions and organizations. From the bulk of literature and policy documents, Ethiopia is an internationally visible country on environmental campaigns more than countries with better domestic achievements on the environmental protection. Unlike the international political leadership for green economy and environmental protection, the country's domestic performances are not fully translated due to policy gaps, institutional dissonance and lack of political will and commitment. Hence, the environmental issues of Ethiopia serve the political agenda than the genuine environmental concern. The research implies the following areas of intervention. Namely, (1) the government needs to work on revising policy documents that correct environmental policy inconsistency. (2) It should also enhance the capacity, efficiency and institutional harmony of environmental protection agencies to realize the environmental goals of the country. (3) The government should give a political will and commitment to the domestic environmental issues like its international commitment and visibility.
\end{abstract}

Keywords: Environmental Politics, Environmental Policy, Ethiopia, Practice

\section{Introduction}

With the growing concern of environmental issue such as climate change, desertification, biodiversity loss, chemical pollution, solid waste pollution, dwindling fish stock and water and air pollution, the worlds' leaders and their people begun to think and speak about environmental protection and conservation. Due to these many international protocols, conventions and declarations are produced. Governments established agencies, branches and structures to carryout environmental protection activities. These developments in international laws enhance the awareness about the fragility of global environment and the immenseness of the problems. Despite these good moves, because of lack of concerted effort and practical commitment the human environment is suffering from rapid environmental change. According to
Mulugeta international soft laws on environment has three broad categories based on their intention in valuation and substance [1]. The first groups are those which are based on exploiting nature for immediate self-interest and aimed at maximizing nature's resource for human use [2, 3]. The second Category is the soft laws that are based up on the principle of sustainable development $[4,5]$. The last category is the contemporary approach, non-anthropocentric paradigm, like the [6].

As argued above, most of the international laws approach and by implication, the national governments inclination on environmental protection is too much anthropocentric. From those international instruments, Bio-diversity convention made a departure by giving primary concern in ecological survival. These international instruments serves as framework to implement programs, resolve disputes, develop national policy and build customary practice on environment. 
Ethiopia is signatory state of many international conventions as one of the leading African state in environmental protection and promotion $[5,7]$. Ethiopia is a country that establishes Environmental protection structure, institution and laws at federal and regional level.

Since 1991 policies and strategies in the country pertaining environmental issues has been formulated, practiced, examined and assessed at different times including the constitution. Researchers like [8-11] were engaged in examining the Ethiopia's environmental issues. Some of their works are associated with MDG's success, issue of Lake Environment and the role of NGO's on environmental protection in Ethiopia. In addition, since the wave of MDGs (Millennium development goals) and the country's growth and transformation plan viv-a-vis with the current SDGs (Sustainable Development Goals), new dynamics of the environmental protection policy and practices of Ethiopia are overlooked and nascent. Therefore, this work focused on the issues of growth and transformation plan in relation with the SDGs. Thus, the paper examines the international environmental experiences and engagements of Ethiopia as well as the domestic environmental policy and practices in the country.

\section{Methodology}

This study attempted to analyze the politics of environment through appraisal of policy and practice in Ethiopia. To address the issue properly, this study employed a qualitative research approach and a content analysis design. In this study, a qualitative research approach is justifiable due to the nature of the research problem, objectives and questions under study. The study employees a wide range of data gathered from multiple sources, which is possible mainly by employing qualitative approach. Thus, the study requires a theoretical perspective, qualitative instruments of data collection and analysis. Beside this, the subject of the study understood by collecting, analyzing and interpreting various documents from secondary sources. International agreements, protocols, conventions, declarations, journal articles and national policies are used. To accomplish this, the researchers employed a qualitative method of data analysis called document analysis.

\section{Conceptual Framework}

From a human point of view, both conventional ${ }^{1}$ and unconventional ${ }^{2}$ institutions restrain human interactions and their attributes [12]. Thus, the environmental institutions of Ethiopia are built in the context in which good consequences are expected by understanding the existing "environmental problems". Different environmental policies and legal frameworks established in countries consider the core problems, effects, and actors in environmental pollution and

\footnotetext{
${ }^{1}$ Constitution, legal framework and policy

${ }^{2}$ Ethics, code of conduct, behavior, custom
}

protection.

Therefore, the view of environmental politics in Ethiopia sticks on the elements of how environmental policies are adopted and implemented. The existing challenges and constraints became the foundation of policies where the purpose is to get out from the problems. Environmental policy benefited highly from the principle stating that, implementation brought impetus to policies - implementation ("the efforts made to execute policies") [12]. The concept and practices of environmental policies has been explained best by the Eugene Bardach machine metaphor- the machine that are linked to make function all, parts must be twisted, available and accessible. Therefore, to function well "a working machine (effective policy) is dependent upon proper design (correct theory); without this, the "machine" will not work, and the desired policy results will not be achieved. Thus, if the correct design (effective policy) is in place, but the necessary parts for policy implementation (essential policy elements) are either lacking or unreliable, then the machine (policy) will be ineffective"[12].

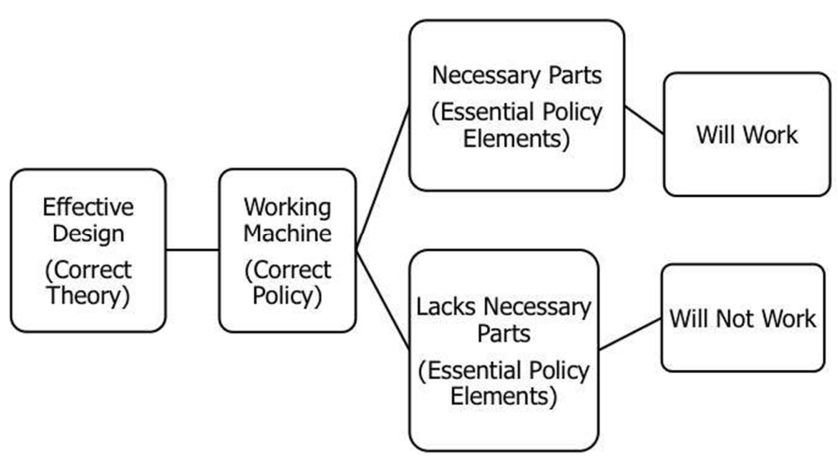

Source: Kefauver (2011), based on Weimer \& Vining, 2005; Bardach, 1977.

Figure 1. Bardach's machine metaphor.

The actors (individual and institutional) will and ability to accept and implement the policies are the major implementation challenges of policy elements. In this respect, environmental policy implementation requires the cooperation of local, regional, national and global actors [12]. Thus, it makes environmental issues complicated that need actors consent and cooperation to realize environmental policy goals in the entire phases of every project.

Government is one of the major actors in environmental protection in developing countries. In this respect, the government of Ethiopia working to convince the international community as an actor in environmental protection with a significant role even in mobilizing the African countries. As a result, the country attracts donors at large. In respect to the images at international level, however, the country's environmental protection achievements are not visible. In spite of this, limited number of researches has been done on the achievements, challenges and opportunities of environmental protection work in Ethiopia. Therefore, this is the effort to appraise the politics of environment- policy and practices of Ethiopia employing the above-mentioned framework. 


\section{Environmental Protection: Concepts, Theories and Issues}

Since recent years, environmental issues are gaining attention and are produced in mass volume. According to Carter [13], literature on environmental issues can be categorized as reformist and radicals that the former approach believed that environmental problems could be resolved without changing the present day patterns of production and the latter is an approach that command for changing the nature of human relation with the non-human world. Apart from the academic attention the rapid and alarming degradation of the planet's natural resource, ecologism is gaining acceptance and expanding from international structure.

The ethical valuation of environment is still problematic in the field of environmental ethics. There is a vast debate on the value of environment whether it is intrinsic or instrumental. Instrumentalists take the nonhuman world as an instrument of human satisfaction and end. Such believe is rooted in the biblical teaching - Adam and his off springs are believed as the master of nature and taking nature as his store house. Since western value which is the extension of enlighten is biblical this arrogance impaired the environmental protection movement by dwarfing the intrinsic value approach. The instrumental approach leads us to mastering, exploiting and manipulating nature to human end. According Elton [14] these value differences creates controversies between environmental protection actors such as actors in their central referents are human being and actors that make their referents include the nonhuman world. In addition the existing knowledge system on environmental protection is too shallow and immediate solution perspective. The widely practiced and common approaches like environmental conservation and preservation are semantically the extension of instrumental approach.

Thinking of environment as Dobson argued in [13] that our ethical relation with the natural world needs to be changed to achieve sustainable societal existence. Environmental issues needs to be grown further to the extent of being political ideology which will offer an alternative perspective compared to the old ideologies; liberalism, conservatism and socialism. Though there are attempts in propagating this ideology in the western world, it is evident that the growth of conservatives after the coming of Donald Trump as American president. Let alone making environmental agenda as the civic issue, its ethical evaluation is not yet resolved.

Following the spread of political activism and strong academic warning against the negligence of environmental issues, several protocols, declaration and conventions and treaties $[2,3,7,15,16]$ signed at international level. The content of these documents support the above arguments. The principles and preambles of these international treaties state the philosophical and ethical resemblance to anthropocentric and instrumental view of the environment.

For example, Basel convention's [17] preamble begins by informing the hazardousness of wastes and the need to manage wastes. It clearly shows that waste management is instrumental for the wellbeing of human health. Similarly, "the Aarhus protocol [18] on trans-boundary air pollution" states the danger of air pollution to human health similar to the Basel convention. The Espoo Environmental Impact Assessment Convention [4] also put the interrelation between environment and sustainable development, which asserts the need of mitigating adverse environmental impacts of economic activities. In the same manner, Kyoto Protocol on climate change [15] states the need to encourage for limited and qualified emission as a means to promote sustainable development. The 1987 Montreal protocol sett obligation for not emitting ozone depleting substances in order to promote the human health, not surprisingly 1992 Rio-declaration on environment and development propagate the human centric approach and laden with instrumental value for environment. The first principle of the declaration stated as "human beings are at the center of concern for sustainable development". Worst of all the Stockholm declaration state man as both creator and molder of its environment in the way environment gives its physical, intellectual, social and spiritual sustenance. The latest convention on environment, the Paris convention [19], on climate change convention depicts priorities for safeguarding food security, ending hunger, and particular vulnerability of food production. Compared to other conventions on environment, the 1992 convention on biodiversity uniquely state the attachment of intrinsic value to biological diversity and the ecological, educational and esthetic value of the environment.

As discussed above most of the international instruments on environmental protection and promotion are too much human centric and instrumental to some other end. The international instruments on environmental protection treat the environment as the means for human fulfillment alone and subject to change, modification, exploitation and manipulation. According to Elliot [14], "what is occurring in our planet is irritating, inconvenient, disappointing and bad". The ethical approach and principle towards environment needs re-examination and revision including the supper structure. This move has urgency to escape from the upcoming giant distracters. Contemporary environmental studies' scholars $[14,20]$ recommended for departing individualistic [instrumental and human centric] valuing of environment from sentiments perspective. It is important to revise the existing supper structure from holism; valuing environment from both sentient and non-sentient perspective.

Practical works towards environmental protection lack transparence as well as commitment. Particularly developed countries assistance for environmental protection is politically motivated and has many conditions. Similarly, the developing countries practice on environment is too poor. An environmental protection project supported by international community lacks transparency in implementation process. Despite their higher contribution to environmental degradation and climate change powerful state of the world 
did not sign and effect these protocols and treaties ${ }^{3}$. Probably this will be the difference in valuation of environment between different cultures and societies. From this, it is possible to argue that the international community is failed to build common outlook and derivative principles, which could inspire national governments in preserving environment. Let alone the instinct and instrumental debates on environmental valuation, the scope of this paper is limited on the Ethiopian practical reality vi-a-vis the existing international and national environmental conventions and policies.

\section{Ethiopia and the International Environmental Visibility: A Real or Pseudo}

Ethiopia is one of the few developing countries, which embedded climate related objectives in to the country's model. The country embarked on an ambitious structural transformation through its successive growth and transformation plans (GTP) and its climate resilience economic strategies. Ethiopia is the country of great potential in its natural resource, due to this it is imperative to integrate environmental and sustainable development. This situation creates both challenges like problem of resilience in rural landscape, green industrialization, sustainable urbanization and sustainable energy access [21]. Ethiopia unlike its international recognition obsolete use of pesticides, spread of alien weeds, over grazing, deforestation of arid areas, water pollution, soil pollution and chemical fertilizers are very common. In Ethiopia, the original natural forest is declining due to expansion of farmland, charcoal production and woods for construction (Ibid). According to Global Environmental financing (GEF) [22] sixteen projects were approved for environmental issue. Though such projects were implemented, it is observed that households are suffered from environment-induced problems. As the researchers' investigation, programs implemented in promoting environmental resilience are not successful if not absent. Among others, clean energy program, sustainable charcoal production, and food security, sustainable landscapes are few of them. In addition, program related to biodiversity conservation and development program, forest landscape restoration, rehabilitation and ecotourism, community based water shad management and other small multifocal projects are unsuccessful which cost big deal of money. This is why the researcher argues that Ethiopia is a country with the big name but poor at practical level in environmental protection agendas.

\section{Environmental Policies and Legal Frameworks in Ethiopia}

The national policies, legal frameworks and practices of environmental protection in Ethiopia discussed below to

\footnotetext{
${ }^{3}$ For example USA withdraw from Kyoto protocol, question the Rio Earth Summit (1992) as well as complain for withdrawing from Paris environmental agreement
}

analyze the policy and legal issues for environmental issues to get lesson in overcoming the challenges in this sector. In this regard, the natural resource protection practices and any other socially important projects should minimize the possible impacts on the environment and maximize the continuous and integrated benefits.

\subsection{The FDRE Constitution}

The Federal Democratic Republic of Ethiopia Constitution ratified in 1995 that have direct and specific section on the environmental protection and rehabilitation issues. It includes the plan and measures of rehabilitation, and measures to mitigate the damages on environment. In its article 40, "land and natural resources is exclusively vested to the state and the peoples of Ethiopia with the right to acquire and use..." [23].

Article 43, 44, and 92 of the constitution also deals with "the right to development", "environmental rights" and "Environmental objectives" respectively. some of these provisions give citizens have the right to improved living standards and to sustainable development (art. 43,1); participate in development activities which shall enhance the capacity of citizens for development and meet their basic needs (art. 43,4); access to a clean and healthy environment (art 44,1 and art. 92,1); get commensurate monetary or alternative means of compensation for displaced or whose livelihoods have been adversely affected by state programs (art44,2); Immune from designs, implementation of programs and development projects that damage or destroy the environment (art. 92,2); participate in full consultation and to the expression of views-in the planning and implementation of environmental policies and projects that affect them directly (art. 43,2 andart92,3); and government and citizens shall have the duty to protect the environment (art. 92,4).

Furthermore, Article 41 concluded, "The State has the responsibility to protect and preserve historical and cultural legacies of citizens and the state at large". Thus, the protection of citizens' sustainable interests got constitutional recognition; hence, the development and environmental issues of the country shall keep the historic and contemporary values of the people at large. Therefore, any environmental issues of the country are required to comply with these and other constitutional principles and provisions [23]. The problem is the constitutional provisions are not observed. Let alone the development issue, the constitutional agents fail to protect the country from visible chemical pollution (artificial fertilizer, pesticides, expired drug, factory influents and solid waste pollutions). Both in the urban and rural people of Ethiopia are exposed to environmental degradation, if not damage.

\subsection{Environmental Policies of Ethiopia}

The 1997 Ethiopian Environmental Policy [24] aimed the socioeconomic development through environmental conservation and sustainable utilization of holistic resources. In its objectives, the policy identifies a range of adopted 
environmental issues and sectoral (agriculture, forest, ecosystem and biodiversity, water resources, energy, human settlement and urban, control of hazardous materials, pollution and climate change, and culture and natural heritage) policies. The overall objective of the policy is "to improve and enhance the health and quality of life of all Ethiopians, and to promote sustainable social and economic development through the sound use of resources of the environment to meet the generations need by keeping the resources for future generation".

In 1999 the Ethiopian water resources management policy was approved to promote the national policy for wellorganized use of water of Ethiopia for the development of the country. However, lack of sustainability, unreliability, and inappropriate utilization, unrealistic and incompatible plans are the problems that exclude the rural context are among the observed constraints. In order to alleviate such constraints the 'Ethiopian Water Sector Policy' is approved in 2001. The policy was devised to serve the country's development in an optimum manner. It considers domestic interests and principles that Ethiopia accepts from the international agreements and principles. Thus, the development of water resources, fair allocation of water resources, managing and combating droughts and floods, and conserving the overall water and aquatic environment sustainably are the five mentioned objectives of the policy [25]. However, weak institutional performances because of policy gap (lack of integrated institutional plans and practices), and low water concern due to lack of political will are observed as a weakness. As a result, river waters, springs and small ponds became vulnerable for overuse and pollution (liquid and solid waste). Among other things, water sources like spring, river, and lakesides are observed as the dumping site of city wastes. Thus from the practice of water policy, different water sources are in the 'process of being extinct' [26].

The study [26] of Sebsib, Mulugeta and Shimelis indicates that water practices are done not in respect with the objectives of the policy. Specifically, different actors like individual and organizations pollute water in the urban environment. Household wastes and emissions are directly depleting the environment caused by poor waste management and weak regulation practices. Though there have been attempts of environmental protection through raising awareness, the researchers found that the channel of communications has been limited only on printed papers and pamphlets, which is limited in access. This time, 'the era of social media', the least costly and the more accessible media especially for the urban community has been left aside from using by the environment protection actors (governmental and nongovernmental).

\subsection{Development Plans vis-à-vis Ethiopian Environmental Policy}

Agricultural Development Led Industrialization (ADLI) is the core rural development policy approved in 2001 to promote agricultural productivity and industrialization. It was planned to apply Green Revolution Technologies and substantive farming were aimed to transform the agricultural production of the country's development; namely, "Technology generation and dissemination; Food security, including resettlement and water harvesting; Agricultural extension and vocational training; Agricultural marketing (of inputs and outputs); Rural finance; Development of cooperatives; Rural transport; and Rural land administration and management" [27]. ADLI explicit emphasis were green technologies for sustained production focused on agroecological zones and land [27]. Therefore, environmental protection agenda were given an implicit consideration.

Ethiopia has been implementing the two consecutive transformation plans covering the period 2010/11-2019/20 to transform the national economy at large. The First Growth and Transformation Plan (GTP I) was among the efforts to achieve the MDGs (Millennium Development Goals). It was planned to achieve "Ethiopia's long vision and sustaining the rapid and broad based economic growth to end poverty" As a result maintaining an average real GDP growth rate of $11 \%$, increase the access and quality of health and education sectors, create favorable conditions for developmental state and ensuring growth sustainability of the above mentioned objectives were the the priority objectives of the GTP I [28].

From the objectives of the plan, it is possible to draw a meaning that insignificantattentions were given for environmental issues, if not non. Because the seven pillars of the plan emphasised on the; economic growth, agricultural transformation, industrial development, infrustructural devevelopment, expand social development vis-à-vis building good governance together with women and youth equitable benefits [28]. Rather environmental issues won less attention than the economic growth and achievements.

Furthermore, environmental damages due to low concern for theprotection and conservation of resources led the country toencure unmeasurable costs. As evidenced in the report of ethiopianreview [29], forest in different parts of the country like monastries were burned. Infrustructural development and constructing industries in different parts of the country contributes to the removal and disturbance of the urban and rural ecosystem [29]. Sugar factory development in the northern ethiopia, particularly, the Waldiba Sugar factory, were the bone of contention between the local community and the government. The issue of environmental concerns were among the reasons that brought the factory to be the issues of political controvercy in the country that invites the diaspora community call for demonstration where environmental protection issues were among the slogans seen in Europe and NorthAmerica. According to Getaw [30], the Addis Ababa light railway project brought a considerable negative environmental effects on the dimentions concerning; "physical recourses, ecological recourses, economics and human recourse, evaluation of living standard". Though one of the GTP I project, Addis Ababa Light railway, were expected to improve the air by replacing the gas emission transport system, the study found that the construction period air quality has been impacted by gases and dust [30]. Furthermore, the surface water disturbance were found with a 
significant impact on the water source caused by dust and excavated materials [30].

The strategic directions of "Environmental Protection and Building Green Economy" sections of the GTP II [31] emphasized in enabling the community to engage in "environmental protection and forest development activities", inter alia, "mixed farming and climate resilient green economy". Thus, major emphases are given to environmental sustainable economic growth by raising the role of forest development through the entire objectives of the second GTP.

As mentioned in the plan, the second GTP is centered on promoting climate resilient green economy that forced every specific sector to have the environmental protection and forest development purposes. At the fall of the period $(2019 / 20)$, forest increments and reduction of GHGs (Green House Gases) are expected to be achieved using the specifically outlined monitoring and follow-up plan [31].

The international and domestic (experts, officials and the public at large) green economy and climate change partners are expected to assure the sustainable development. However, since 2015/16 vegetation activities like planting and nurturing the seed plant are found in poor achievement [26].

Under the promulgation of GTP II, the "Ethiopia's Environmental and Social Safeguards Framework (ESSF) for the CRGE (Climate Resilient Green Economy) initiative" were declared by Ministry of Environment, Forest and Climate Change to succeed in climate resilient green economy purposes. Specific considerations of the framework are to set the environmental standard for safe investment, manage the harmful effects of investments on the environment and mobilizing actors in implementing the principles $^{4}$ of green investment initiatives in the entire cycle of the projects [32].

Three years after the implementation of Climate Resilient Green Economy initiative, the "Country Environmental Analysis (CSA)" indicates that the country's "resilient green transformation" goals are faced with different challenges; in the word of [12], it is the policy that "lacks necessary parts (essential policy elements)". Thus, environmental policies are faced with policy and legal framework challenges; the 2002 enacted "environmental impact assessment proclamation" and the "environmental pollution control proclamation" does not have any formally approved regulations, guidelines and standards that are applicable in respect with the local government contexts [21]. Besides the authoritarian instruction and controlling methods used, the proclamation has been applied through "delegation of power to sectoral ministers" where institutional coordination were undefined and weak, and information were not disclosed to the public at large in the formulation of policies and implementation of projects. The other institutional challenge is weak capacity to

\footnotetext{
${ }^{4}$ In the MEFCC (2015) document, the general principles of Climate Resilient Green Economy are "Early application of environmental and social safeguards, Participation of stakeholders, Information Dissemination, Prevention and mitigation of adverse impacts, and Accountability and Transparency".
}

review environmental impact assessment and institutional and structural instability due to budge and expertise constraints [21].

Therefore, the "Ethiopia's Environmental and Social Safeguards Framework (ESSF)"is one of the showcase of the government's attention for environmental protection in the GTP II. Currently in the fall of the plan, however, environmental protection is not such an achievement rather constrained by the unavailability of parts for the complete or greater success of the environmental policy concerns. Furthermore, the GTP II is faced with challenges that weaken the institutional capacity to realize the environmental protection agenda. These challenges are high inflation, worsening political turmoil, dissonance institutions, weak institutional harmony, and low savings and shortage of hard currency.

High inflation- in the fall The GTP II mixed reflections are observed, achievements below the expected and total failure of the plan, due to the current national political context. The main idea of this statement is that GTP II is faced with impediments the so-called high inflation vis-à-vis environmental issues. In the period, the rate of inflation at national level has been rising to the extent that the national development bank could not have hard currencies to the overall economic purposes. Therefore, environmental protection projects are assumed to be influenced as like as many other national plans.

High political turmoil- that pressured the national efforts diverted from the environmental protection concern. Furthermore, the political instability worsen the environmental harm by letting companies and giant project sites and institutions to be burnt down that contributed its own share to the failure of the environmental plan in the period. Unlike the "forest development activities", and community watershed program planed in the period, mountains and forests were burnet several times. Semein Mountain National Park constitutes of $220 \mathrm{~km}^{2}$, of which 343 hectares of the park are destroyed by fire in three days of fire by 2019. As a result, currently Ethiopia is running to be a "Roof of Africa forest burns" [33], due to political negligence and poor institutional responses of the country. This indicates that, there is poor technical efficiency of environmental protection institutions in the country in general and in the region in particular. In addition to this, the political context of the country has been also the causes for the damages of significant forest sources. Therefore, national parks are in danger of losing due to environmental policy failure. Thus, the park became a field for informal settlement area, grazing, plowing, large-scale agricultural bases (Gambela National Park) Mohammed Seid and Behailu Taye [34] and construction of huge energy investment in Omo National Park.

Low domestic savings and shortage of hard currency- put constraints to the engagement of governmental and nongovernmental actors on the environmental issues. As a result, it gives unjustifiable reason for the government to lessen down the attention to environmental issues. However, 
there is an attempt in the capital city, Addis Ababa, Sheger River Project to greening the city.

Weak institutional harmony- The plan gives specific priorities to forest development activities, however except the declared seedling activities, which has been carried out every June. The seed nurturing and sustainable follow-up and ownership responsibility activates are left aside or ignored by the local government sectors. As a result billions of seedlings (4 billion in 2011 E. C) which incur the country to cost a million dollars. Therefore, weak institutional harmony is among the visible challenges that the plans are faced through the entire period.

Institutional Dissonance-the success of a project is dependent on the technical qualities employed; thus, the development and execution of projects should consider the horizontal and vertical relationship with organizations and institutions. Thus, quality project meet the technical quality of institutions, where lack of coordination is observed in practice [30]. As a result the environmental issues are faced with iminent challenges due to lack of harmony among institutions that have environmental concerns and interests beginning from defining common interests and implementation phases.

Generally the GTP I \& GTP II (in the fall), has success in economic growth, however, it is noted that the period are criticized with poor environmental protection achievements. Besides the above discussed purposes and challenges pertaining the objectives; the issue of week institutions, disharmonious relationship among the concerned organizations and agencies vis-à-vis grand corruption, investor appeasement and the types of industries or investments migrated to Ethiopia (horticulture and textile) investments affect the environment seriously.

\section{The Ethiopia Envisioned 2025 Development Trajectories and Environment}

Ethiopia planed to attain structural transformation by 2025 - to be one of the middle-income countries of the world. Thus, industry is highly expected to grow faster than the service and agriculture. The plan has key clusters "resilient landscapes, green industrialization, sustainable urban development, transport and living conditions, and sustainable energy access" FDRE Environmental Protection authority [21]. Thus, three clusters are planned to serves the environmental sustainability purposes.

"Ethiopia ranks highest in political leadership in green economy and climate change. But, political intent is still not fully translated into environmental performance, particularly in the area of markets and investment" FDRE Environmental Protection authority [21]. Regardless of high images and political visibility of Ethiopia at the global environmental scene, the country's environmental achievements are below the record of Kenya, Ghana and Mozambique; countries with less international visibility on environmental issues [35].
The current policy projection result of 'Climate Action Tracker' ${ }^{5}$ shows that Ethiopia became one out of countries that have long term targets and short term policies to limit the warming by $1.5^{\circ} \mathrm{C}$ by minimizing deforestation scale, and maximizing the forestation and reforestation measures. However, the Ethiopia government commitment is not at all consistent with the Paris Environmental Agreement $\left(1.5^{\circ} \mathrm{C}\right)$. Therefore, if the Ethiopia government measures goes similar with the current trend, then by the 2025 the country's warming would increase by $3-4^{\circ} \mathrm{C}$. This shows that the country's environmental policy and practice lacks important aspects (implementation and policy gap) that prevent the country's GTP II from the realization and the 2025 green transformation will be impacted highly. As a result, the country's environmental visibility became associated highly with the political significances at international arena and domestic political affairs.

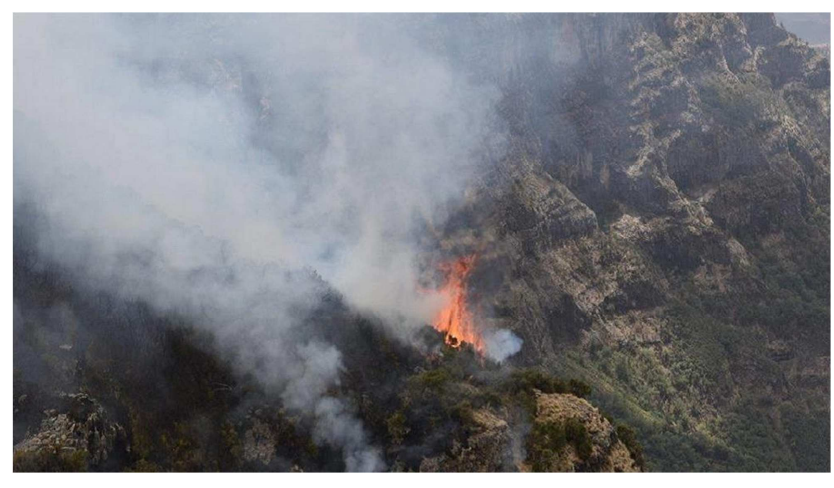

Figure 2. Semien National Park, Africanews (2019).

\section{The Implication of Environmental Policy Implementations}

Ethiopia's environmental protection policy and practices has been the agenda for several years at international and national level. As a result, the country launches different environmental protection and sustainable development agendas since 1991. The country's experience in making different issues of environment as an agenda would let the country to face with lack of new agenda in the near future.

As a result, the country may face with the predicament of salvage agenda. The legacy offailure may continue to surface to the extent that keep weak images of the government and harmcitizen's trust pertaining the environmental agenda. Therefore, the current failure and its spillover effect would have a negative impact that may influence the country's effort on making environmental issues to be the agenda of the state and the international community at large.

The challenges in environmental protection plan of the country cannot be assumed as an impact-less experience; rather, the impediments of environmental policy in Ethiopia became a challenge to the development projects. According

\footnotetext{
'Climate Action Tracker', Country Assessments 2018 https:/climateactiontracker.org/countries/ethiopia/current-policy-projections/
} 
to Johannes and Reiher [36], the policy brought an increase of rainfall variability. It resulted in pervasive flooding and drought with an increase in occurs that are highly associated with global warming. In addition to the above mentioned climate change related problems, the country suffered from scarcity in water, sanitation and hygiene. Water is not evenly distributed. Thus, the country has the lowest artificial water storage and supply. Accordingly $62 \%$ and $88 \%$ of the population are living without access to water and sanitation respectively [36].

Furthermore, energy shortage, desertification and poor land management that brought to degradation are among the showcase of policy gaps. As a result, $85.1 \%$ of the people are living without access to electricity [36]. Currently Ethiopia has begun power rationing due to the shortages of power. The electric power rationing affects the country's domestic socioeconomic activities. This electric power shortage is the result of climate change that resulted in lack of sufficient water. Thus, dams in the country generate electricity, which resulted in $460 \mathrm{MW}$ power shortage. Insufficient water volume that flew from the country's highlands became downsized twice, beyond the expected [37]. Concomitant to the above mentioned environmental policy gaps, maintaining and expanding forest development in Ethiopia highlands became less successful. As a result, the country is forced to take the second measure; revising power management agreement with the neighboring countries. Thus, power sale to Sudan is suspended, while half reduce power supply to Djibouti [37]. This implies that the country's external environmental protection visibility and domestic achievement practices are far from the established images at the international level which may in long run damage the global image of the country.

Today, the livelihood of $72 \%$ of the people's are dependent on the degraded land where the subsistence agricultural productivity became affected and resulted to livelihood insecurity and poverty in the rural Ethiopia [36]. As a result, the resource dependent economy of sub-Saharan Africa in general and Ethiopia in particular leads to growth and development loss. Thus, the environmental failure became the major challenges of the country's development goals.

\section{Conclusion}

The article introduced the politics of environmental policy and practices in Ethiopia since 1991. The international environmental engagement of Ethiopia vis-à-vis its domestic performances are the center of the review. Regulations towards environmental protection are governed by anthropocentric, holistic and ecocentric perspectives depending on the instrumentalist and intrinsic values of the environment. Based on these perspectives and values, different international conventions and domestic policies were ratified and implemented by countries of the world.

Using document analysis, the review found that Ethiopia is a country which establishes environmental protection structure, institutions and laws. However, the country is not effective in its domestic performance as effective as its international visibility. Nevertheless, the country's 1995 FDRE constitution give an emphasis on the environment under the right to development, environmental rights and environmental objectives sections. Thus, citizens sustainable interests got constitutional recognition where state share the highest responsibility to protect and preserve the historic and cultural legacies of citizens at large.

Since 1991 different environmental protection policies and strategies were adopted and implemented with the purpose to raise citizen's benefit from the environment. At the same time plans and policies of the country give emphasis on the protection of the environment as well as maximization of citizen's benefit by lowering the concern for environment. ADLI and GTP I were focused on the transfer of technology and eradication of poverty at large. As a result, an explicit consideration and emphasis were not given for environmental protection purposes. The GTP II is among the plan to transform the country in a multidimensional ways. As a result, the plan provides a direction on building green economy by emphasizing on environmental protection issues. As a result, forest development through minimizing deforestation, and maximizing the reforestation and a forestation activities has been the concern of the plan. However, the strategic directions of the plan have been practiced with limitations. Furthermore, the country's resilient and green transformation plan has been challenged by lack of essential policy elements. As a result the environmental policies of Ethiopia became affected by policy, legal framework and practice challenges.

The practical challenges of the environmental protection goal of Ethiopia are; lack of institutional linkages, lack of clear authority for institutions, lack of branch offices at local level and weak institutional capacity. Furthermore, the GTP and other environment protection policies have been challenged by different constraints at national and regional level. These challenges are high inflation, political instability and conflict, dissonance institutions, weak institutional harmony and low saving and shortage of hard currency.

The above mentioned challenges and its spillover effect would harm the 2025 country's vision- to be a middle income county with "resilient landscape, green industrialization, sustainable urban development and living conditions".

The review found that Ethiopia's international environmental leadership roles are inconsistent to its domestic achievements. Regardless of the country's visibility and international environment scene, the country's achievements are below the record of countries with less visibility at international environmental issues. Currently, the country's achievements are not in consistent with the promise that Ethiopia made at Paris Environmental Agreement $\left(1.5^{\circ} \mathrm{C}\right)$. Thus the research concludes that the country's environmental visibilities are associated highly with the political significances at international arena and domestic political affairs.

The limited environmental protection activities of the country can't be assumed an impact less experience; rather 
the impediments may challenge the development goals. In this regard the availability of basic needs (water, food and shelter) may face an obstacle. At the end these challenge may brought failure from providing an adequate living standard for citizens. The research implies the following areas of intervention. Namely, (1) the government needs to work on revising policy documents that correct environmental policy inconsistency. (2) It should also enhance the capacity, efficiency and institutional harmony of environmental protection agencies to realize the environmental goals of the country. (3) The government should give a political will and commitment to the domestic environmental issues like its international commitment and visibility.

\section{References}

[1] Mulugeta Getu (2012) THE ETHIOPIAN ENVIRONMENTAL REGIME VERSUS INTERNATIONAL STANDARDS: POLICY, LEGAL, AND INSTITUTIONAL FRAMEWORKS; Haramaya Law Review; Vol 1-1, (page 4270).

[2] UN (2001). Stockholm Convention on Persistent Organic Pollutants.

[3] UN(1992). Paris Agreement, United Nations Framework Convention on Climate Change.

[4] UNTC (1991) Convention on Environmental Impact Assessment in a Transboundary Context; (Finland).

[5] UN (1994) Montreal Protocol on Substances that Deplete the Ozone Layer (as agreed in1987) Montreal, Canada, http://www.lawcommission.gov.np/np/.

[6] UN (1992) Convention on Biological diversity.

[7] UN (1992). The Rio Declaration On Environment And Development (1992); The United Nations Conference on Environment and Development, Having met at Rio de Janeiro.

[8] Dominik, W. S. (2010). Evaluation of the environmental policy and impact assessment process in Ethiopia: Impact Assessment and Project Appraisal, 28 (1), March 2010, pages 29-40 DOI: 10. 3152/146155110X488844; http://www.ingentaconnect.com/content/beech/iapa.

[9] Edwards S. (ed) (2010) Ethiopian Environment Review, FORUM FOR ENVIRONMENT ADDIS ABABA, ETHIOPIA.

[10] Colby Environmental Policy Group. 2011. Environmental Policy Review 2011: Key Issues in Ethiopia 2011. Waterville, Maine: Colby College Environmental Studies Program.

[11] Tenalem Ayenew. (2004). Environmental implications of changes in the levels of lakes in the Ethiopian Rift since 1970. pringer-Verlag.

[12] Kefauver (2011). Environmental Policy Review 2011: How Environmental Policy Facilitates or Constrains the Activities of Environmental NGOs in Ethiopia.

[13] Carter (2007). Critiquing environmental management in indigenous Australia: two case studies, Royal geographical society, V. 39 (1), Willy Online library.
[14] Elliot, R. (2001). Normative Ethics (Ed) in Jemison, A companion to Environmental Ethics (177-192), Blackwell Publisher, Ltd.

[15] UN (1998) Kyoto Protocol to the United Nations Framework Convention on Climate Change.

[16] UNEP (2006). ROTTERDAM CONVENTION: on the Prior Informed Consent Procedure for Certain Hazardous Chemicals and Pesticides in International Trade.

[17] Conference of the Plenipotentiaries (1992) Basel Convention on the Control of Tran boundary Movements Of Hazardous Wastes And Their Disposal Adopted By The Conference Of The Plenipotentiaries On 22 March 1989.

[18] UN (1998). Protocol to the 1979 convention on long-range trans-boundary air pollution on persistent organic pollutants, Denmark.

[19] UN (2015). Paris Climate Conference.

[20] Singer (2001). Introduction: Choosing among nonspeciouscist ethics (Ed) in Jemison, A companion to Environmental Ethics (416-426), Blackwell Publisher, Ltd.

[21] FDRE Environmental Protection authority(2017), Country Environmental Analysis (CEA), Ethiopia Realizing Green Transformation: World Bank, Ethiopia Environment and climate research center and Ethiopia development research institute.

[22] Global Environmental Financing (GEF) (2011). Annual Performance Report.

[23] FDRE Constitution. (1995). the Constitution of the Federal Democratic Republic of Ethiopia. Addis Ababa: FEDERAL NEGARIT GAZET A.

[24] FDRE Environmental Protection policy (2011). GEF Pollution Identification document, AA. Ethiopia.

[25] Ministry Of Water Resources (2001) Ethiopian Water Sector Policy, Addis Ababa, Ethiopia.

[26] Sebsib, Mulugeta and Shimelis (2019). Local Water Governance in the case of Borkena River: Trends, actors and Human Security issues. Dessie, Amhara Region, Ethiopia. (unpublished).

[27] Kenichi. (2009). ADLI and Future Directions forIndustrial Development.

[28] MoFED (2010). Ethiopia's First Growth and Transformation Plan (GTP I) 2010/11-2014/15, 2010).

[29] https://ethiopianreview.com/contet2012.

[30] Getaw (2017) Post Completion Sustainability of Ethiopian Railway Project: The Case of Addis Ababa Light Rail Transit Project (AALRTP) - Scientific \& Academic Publishing. , Management, 7 (1): 7-28.

[31] National Planning Commission (2016). Federal Democratic Republic of Ethiopia. Growth and Transformation Plan II (GTP II) (2015/16-2019/20) Volume I. Addis Ababa, Ethiopia.

[32] MEFCC (2015) ETHIOPIA'S ENVIRONMENTAL AND SOCIAL SAFEGUARDS FRAMEWORK (ESSF) FOR THE CRGE INITIATIVE": Ministry of Environment, Forest and Climate Change; Addis Ababa, Ethiopia. 
[33] https://www.africanews.com/2019/04/14/ethiopia-s-roof-ofafrica-forest-burns-israel-joins-fire-combat.

[34] Mohammed Seidand BehailuTaye (2019) Impacts of human activities on wildlife: The case of Nile Lechwe (Kobusmegaceros) Gambella National Park, Southwest Ethiopia; International Journal of Biodiversity and Conservation.

[35] Tamanini (2016). The global green economy index:
Measuring national performance in the green economy. 5th edition-September 2016. Dual citizen LLC, USA.

[36] Johannes and Reiher(2013) Green Economy in Sub-Saharan Africa; Lessons from Benin, Ethiopia, Ghana, Namibia and Nigeria; Deutsche Gesellschaftfür Internationale Zusammenarbeit (GIZ) GmbH.

[37] https://www.ezega.com/News/NewsDetails/7101/EthiopiaHit-by-Power-Shortages-Reintroduces-Rationing. 